\title{
AVAILABILITY OF INSTRUMENT AND MATERIAL IN THE ORTHODONTIC CLINIC, FACULTY OF DENTISTRY UNIVERSITY OF MALAYA- AN AUDIT
}

\author{
Ab Rahman N, Wan Hassan WN. Availability of Instrument and Material in the Orthodontic Clinic, Faculty of Dentistry \\ University of Malaya- An Audit. Annal Dent Univ Malaya 2014; 21(1)
}

\begin{abstract}
The audit aimed to investigate the availability of orthodontic instruments and materials at Faculty of Dentistry, University of Malaya. The standard was set as $100 \%$ of instruments and materials should be available when required for orthodontic treatment. The form comprised of six sections, which listed the commonly used instruments and materials involved in the procedures of impression taking, fitting and removal of molar bands, bonding and debonding of orthodontic brackets and activation of orthodontic appliances. The fifth section listed the less commonly used instruments and materials and a part for the clinician to list down instruments that were used but not listed in the form. Whilst the last section is for the clinician to list down the instruments or materials that were not available when requested. A total of 567 forms were completed and it was found that $97.6 \%$ instruments and $98.6 \%$ materials were available. Overall, 22 types of instruments were temporary not available with frequency mean of 2.1 (Minimum: 1; Maximum: 7) whilst 6 types of materials were temporary not available with a frequency mean of 2.3 (Minimum: 1; Maximum: 8). In conclusion, majority of the instruments and materials required during orthodontic clinical sessions were available. The check list of frequently used orthodontic instruments and materials from this audit could aid inventory and help future management of the material and instruments.
\end{abstract}

Keywords: Orthodontics, instruments, materials, inventory

\section{INTRODUCTION}

Orthodontic instruments included tools to examine patient's records procedure such as impression and photography, bonding and banding fixed appliance and activation of orthodontic appliances. Essentially, there are five components to fixed appliances, which are archwires, bracket/bands, bonding/banding agents, elastomerics and auxiliary components.

According to a survey by Zreagat et al., 2013, there is a high level of need for orthodontic treatment among 12 and 16 years old Malay children in Malaysia (1).The findings showed that $51.4 \%$ of 12 -year-old school children had definite need for treatment (DHC $>4$ ) while $22 \%$ of them desired treatment. Among 16-year-old subjects, $56.4 \%$ showed definite need for treatment while $47.2 \%$ desired treatment. Due to the increased number of patients requiring orthodontic treatment which leads to high

\section{Original Article}

\author{
Ab Rahman $N^{1}$, Wan Hassan $W N^{2}$ \\ ${ }^{1}$ Orthodontic Unit, School of Dental Sciences, \\ Universiti Sains Malaysia, 16150 Kubang Kerian, \\ Kelantan. \\ ${ }^{2}$ Department of Paediatric Dentistry and \\ Orthodontics, Faculty of Dentistry, University of \\ Malaya 50603 Kuala Lumpur. \\ Corresponding Author: \\ Dr. Norma Ab Rahman \\ Email:normaabrahman@gmail.com
}

patient volumes, orthodontic instruments are subjected to frequent use than other common dental instruments (2). During orthodontic clinical sessions, the common cited problems were the unavailability of instruments and materials due to temporarily being unavailable at the time of need. Other complaints were related to the quality of instruments used such as blunt distal end cutter, scratched photographic mirror and corroded instruments resulting in delay in clinical management.

The rationale for this audit was to create a checklist of frequently and commonly used instruments and materials used in orthodontic clinics to aid inventory and help future management of the material and instruments. The availability of the instruments and materials for orthodontic use results in shorter chair side with each patient and can increased efficiency due to reduced treatment time with each patient.

The aim of this audit was to investigate the availability of the orthodontic instruments and materials used by specialists and postgraduate students at the Faculty of Dentistry, University of Malaya. The standard was set as $100 \%$ of all instruments and materials should be available when required for orthodontic treatment.

\section{METHODS}

The audit was carried out at two main clinics within the Faculty of Dentistry, University of Malaya; the Orthodontic Specialist Clinic and the postgraduate clinic (Klinik Pasca Ijazah). All orthodontic specialists and postgraduate students were invited to participate in this 
audit. It was conducted between ends of March until May 2012. This audit was conducted using forms containing the list of instruments and materials commonly used during orthodontic treatment. The form comprised of six sections, which listed the most commonly used instruments and materials involved in the procedures of impression taking, fitting and removal of molar bands, bonding and debonding of orthodontic brackets and activation of orthodontic appliances. The fifth section listed the less commonly used instruments and materials and a part for the clinician to list down instruments that were used but not listed in the form. Whilst the last section is for the clinician to list down the instruments or materials that were not available when requested. All clinicians were asked to complete the form for every patient immediately after treatment. SPSS version 12.0 was used for the data entry and processing. Data analysis was performed by using descriptive statistic.

\section{RESULTS}

Nine clinicians (four orthodontic specialists and five postgraduate students) participated in this audit and completed a total of 567 forms. The evaluation done was based on availability of instruments and materials, instruments and materials that were unavailable and instrument and materials that were not listed but requested by clinicians.

i) Availability of Orthodontic Instrument

About 97.6\% instruments were available when required during the clinical audit period. Examination and diagnosis set which included mouth miror, tweezer and probe were the most popular basic instruments requested in the orthodontic clinic followed by Weingart pliers, distal end cutter, ligature cutter and mosquito forceps. Cinch-back pliers, headgear and mini-implant sets were the less frequently requested instruments over this clinical audit period (Figure 1).

ii) Availability of Orthodontic Material

The result showed $98.6 \%$ materials were available when required which included the general materials, archwires, brackets and bands. Elastomeric modules, composites, alginate and GIC cements were the most commonly used materials whereas the intra-arch elastics, Kobayashi hooks and lingual cleat were the less common materials requested during the audit period (Figure 2). The most frequently requested archwires at both clinics were 0.014 " nickel titanium (NiTi) archwires followed by 0.018 " NiTi and 0.016 " NiTi while 0.019 " x 0.025 " stainless steel (SS) was the most requested archwires used among the stainless

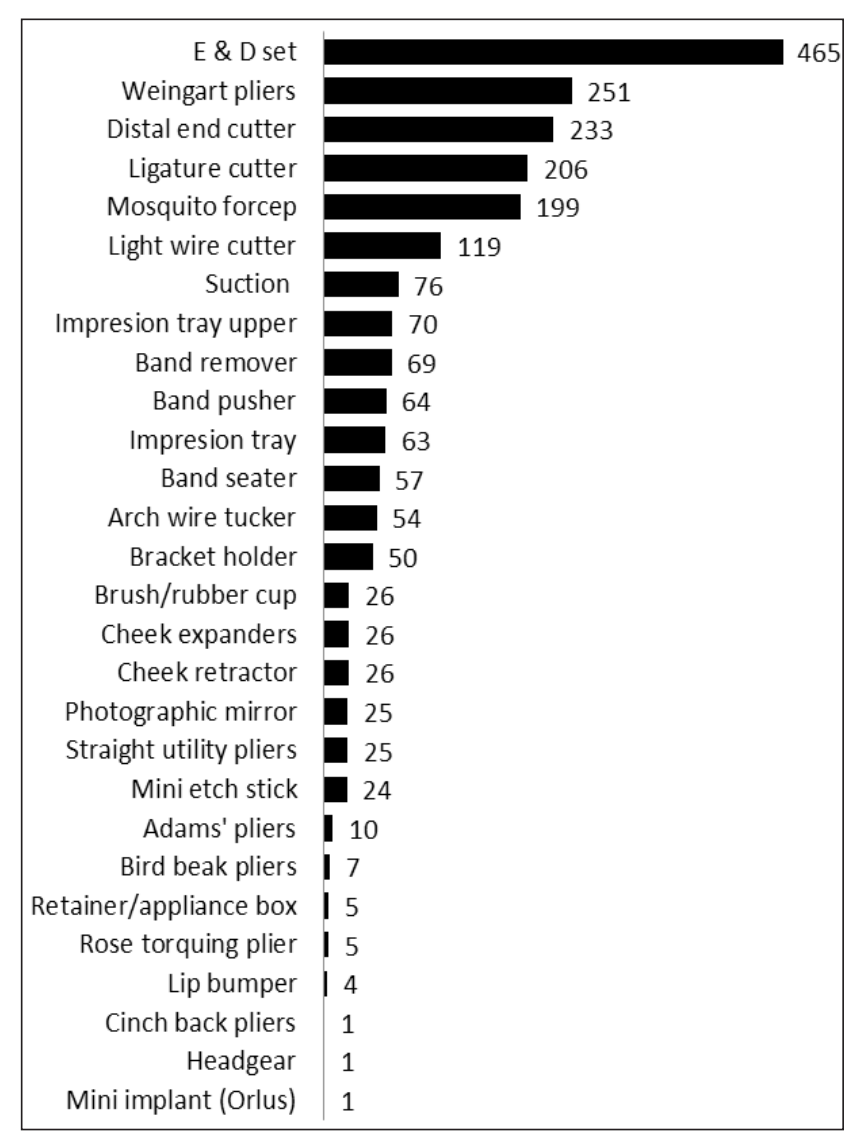

Figure 1: Instruments request during the audit period \{Examination and diagnosis (E\&D)\}

steel wires. The conventional bracket systems were the most frequently used for bond-up (64\%) followed by self-ligating bracket system by Innovation-R (23\%) and Damon self-ligating brackets (about 10\%).

iii) Instruments and materials which were unavailable 22 types of instruments were not available with a frequency mean of 2.1 (Minimum: 1; Maximum: 7) whilst 6 types of materials were not available with frequency mean of 2.3 (Minimum: 1; Maximum: 8) when requested during the clinical sessions. Innovation-R bracket opening pliers, tungsten carbide bur, clinical ruler, slow-speed handpieces and debonding pliers were found to be the most needed instruments but were not available when requested at the clinic. Materials that were temporary unavailable included dental floss, separators, intra-arch elastics, archwire sleeves and acid-etch (Figure 3).

iv) Instrument and materials which were not in list but requested

Overall, all clinician did not request instrument and materials which were not listed in the form during the audit period. 


\begin{tabular}{|r|r|}
\hline Elastic modules & 178 \\
Composite & \\
Alginate &
\end{tabular}

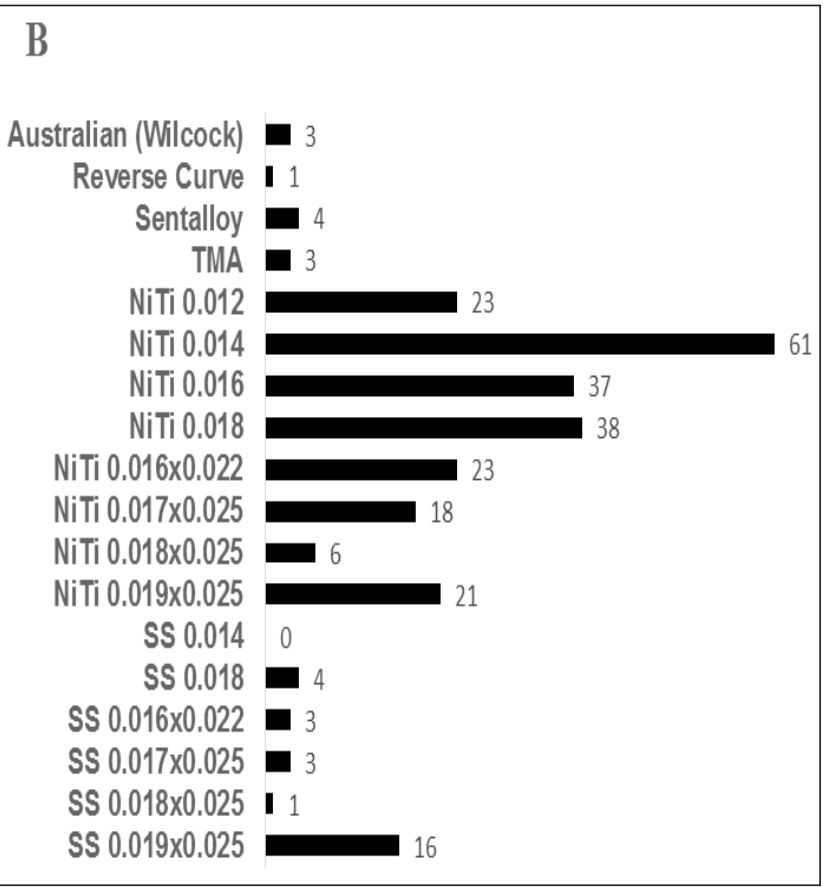

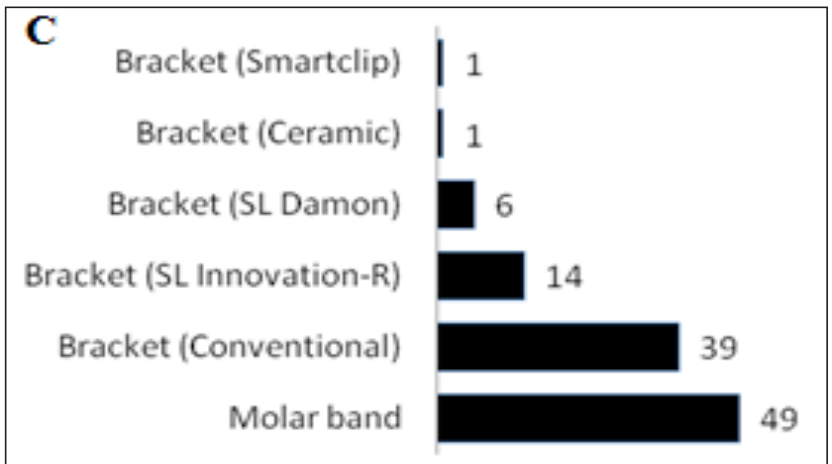

Figure 2: Materials request during the audit period, which includes the (A) general materials, (B) archwires and (C) brackets and molar bands.

\{Glass ionomer cement $(\mathrm{GIC})$, stainless steel (SS), nickel titanium (NiTi), titanium molybdenum alloy (TMA)\}

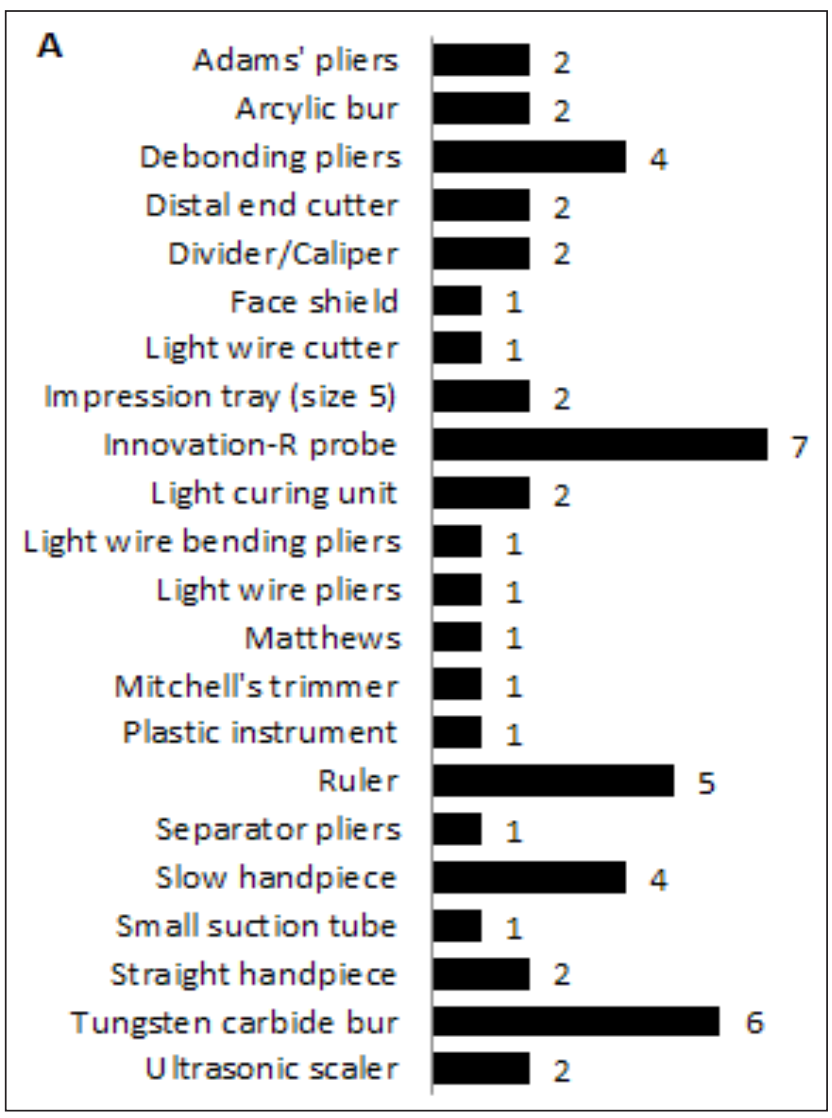

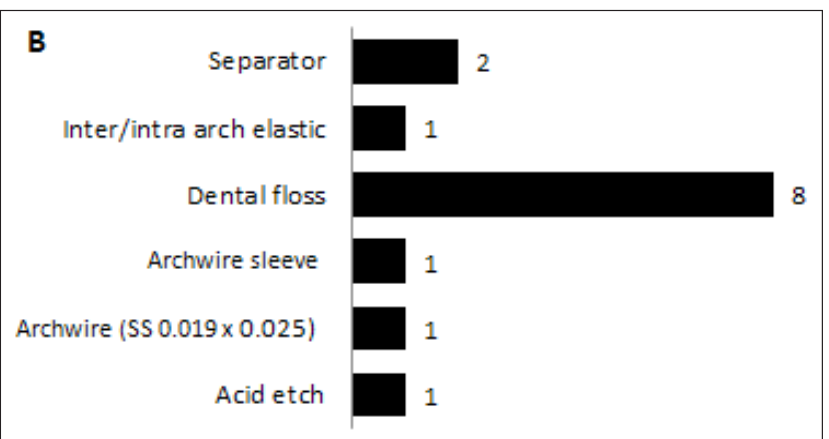

Figure 3: $(A)$ Instruments and $(B)$ materials that were required by the clinicians but were not available during the clinical session. 


\section{DISCUSSION}

At present, there is no published clinical audit on the availability of orthodontic instruments and materials. Generally many audits on instruments focused on instrument sterilization and management. Due to high volume of orthodontic patients treated at orthodontic clinics, orthodontic instruments are subjected to frequent sterilization cycles (2). Insufficient of instruments has resulted many complaints from the orthodontic specialists and postgraduate students. It is known that each instrument has specific application. Therefore, instruments that are needed for important procedures but were not available resulted in increased chair side time, reduced work efficiency as well as increased in frustration and stress levels among clinicians.

From this audit, the total patient seen at the orthodontic clinic in University of Malaya over the two month period was 576 patients. The standard set that $100 \%$ of the orthodontic instruments and materials should be available when requested was not achieved. In total, 2.4\% of instruments and $1.4 \%$ of materials were not available when requested during the clinical audit. This may be due to factors such as high patient load for every clinical session and insufficient instruments. Consequently, instruments are subjected to frequent sterilization and require time before they can be re-used for the next patient. Some instruments may have been subjected to wear and tear resulting in blunt cutting edges, corrosion and scratching and thus, they are not available for use and need to be replaced. Out of stock materials also require time for repurchase and thus may not be available during the time of need.

Based on this audit, a checklist of important and commonly used orthodontic instruments and materials was developed. This is beneficial for inventory of the orthodontic instruments and materials at the faculty. When purchasing for the instruments and materials, there are several factors that need to be considered such as cost, quality of the product, warranty and expiration date. When choosing orthodontic instruments, the determining factor should not be based on price alone. Nowadays, there are many similar instruments manufactured by different companies, each with varying differences that affect the quality and life expectancy of instruments. Different grades of material, finishing, and manufacturing processes distinguish the quality of one instrument over another. In many instances, the price of an instrument is not reflective of the quality received, which is an important aspect to consider when selecting instruments for use. Instruments may also appear similar but have different applications. Instruments should also be bought for correct application for the instruments to work properly and maintain their function for an extended period.
Few recommendations have been proposed from this audit which includes:

1. To purchase orthodontic instruments and materials based on demand and requirement. This process should be done regularly to ensure all relevant orthodontic instruments and materials are available when needed.

2. To periodically run a similar audit of all instruments and materials to monitor for rusted, corroded, chipped, blunt and/or scratched surfaces that may further assist in maintenance of the quality of instruments used on patients.

3. To educate and remind clinicians and orthodontic assistants to ensure correct application for each type of instruments. This would aid in increasing the longetivity of the instruments' life-span hence save cost to re-purchase instruments.

4. To pack the instruments based on the orthodontic procedure to avoid sterilization of unused instruments that were packed together with those that were used. This may help to prolong the life of the less frequently used instruments.

\section{CONCLUSION}

The availability of orthodontic instruments and materials is an important aspect in the field of orthodontic because it can affect the orthodontic treatment and outcome. It was found that, majority of the instruments and materials required during the clinical sessions were available during the clinical sessions over the audit period. However, the standard set was not achieved. A checklist of frequently used orthodontic instruments and materials from this audit could be a beneficial guidance for inventory purposes to improve the standard of instruments and materials that should be available at the orthodontic clinic. A re-audit should be conducted once this issue has been addressed.

\section{ACKNOWLEDGEMENTS}

Special thanks to all orthodontic specialists and postgraduate students at Faculty of Dentistry, University of Malaya who participated in this audit.

\section{REFERENCES}

1. Zreaqat M, Hassan R, Ismail AR, Ismail NM, Aziz FA. Orthodontic Treatment Need and Demand among 12- and 16 Year-Old School Children in Malaysia. OHDM 2013; 12(4):217-221. 
2. Cook A. Investing in your instruments: choosing your orthodontic instruments is about more than just price. The Dental Assistant Publisher: American Dental Assistants Association 2008; 77(6).

3. Abdullah AAA. Orthodontic Material Usage Among Malaysian Orthodontists. Sains Malaysiana 2011; 40(11): 1313-1317.
4. Berardo N, Saglimbene R and Hackensack NJ. Preoperative inventory of orthodontic appliances. Oral Surg Oral Med Oral Pathol 1991; 72(2): 165-6.

5. William A. How to write and analyses a questionnaire. Journal of Orthod 2003; 30: 245-252.

6. Metcalfes S. Clinical audit annual report. University of Bristol, 2008. Report. 